\title{
Solar Sail Science Mission Applications and Advancement
}

\author{
Malcolm Macdonald ${ }^{* 1}$ \\ Advanced Space Concepts Laboratory, University of Strathclyde, Glasgow G1 1XJ, Scotland, E.U. \\ Colin $\mathbf{M}^{\mathrm{c}}$ Innes $^{2}$ \\ Advanced Space Concepts Laboratory, University of Strathclyde, Glasgow G1 1XJ, Scotland, E.U.
}

\begin{abstract}
Solar sailing has long been envisaged as an enabling or disruptive technology. The promise of openended missions allows consideration of radically new trajectories and the delivery of spacecraft to previously unreachable or unsustainable observation outposts. A mission catalogue is presented of an extensive range of potential solar sail applications, allowing identification of the key features of missions which are enabled, or significantly enhance, through solar sail propulsion. Through these considerations a solar sail application-pull technology development roadmap is established, using each mission as a technology stepping-stone to the next.

Having identified and developed a solar sail application-pull technology development roadmap, this is incorporated into a new vision for solar sailing. The development of new technologies, especially for space applications, is high-risk. The advancement difficulty of low technology readiness level research is typically underestimated due to a lack of recognition of the advancement degree of difficulty scale. Recognising the currently low technology readiness level of traditional solar sailing concepts, along with their high advancement degree of difficulty and a lack of near-term applications a new vision for solar sailing is presented which increases the technology readiness level and reduces the advancement degree of difficulty of solar sailing. Just as the basic principles of solar sailing are not new, they have also been long proven and utilised in spacecraft as a low-risk, high-return limitedcapability propulsion system. It is therefore proposed that this significant heritage be used to enable rapid, near-term solar sail future advancement through coupling currently mature solar sail, and other, technologies with current solar sail technology developments. As such the near-term technology readiness level of traditional solar sailing is increased, while simultaneously reducing the advancement degree of difficulty along the solar sail application-pull technology development roadmap.
\end{abstract}

Keywords:

Solar Sail; Mission Applications; Technology Development; Advancement Degree of Difficulty

\section{Introduction}

It is an accepted phenomenon that the quantum packets of energy which compose Sunlight, that is to say photons, perturb the orbit attitude of spacecraft through conservation of momentum; this perturbation is known as solar radiation pressure (SRP). To be exact, the momentum of the

\footnotetext{
* Corresponding Author

Email address: malcolm.macdonald.102@strath.ac.uk \{First Author\}, colin.mcinnes@strath.ac.uk (Second Author\}, space@strath.ac.uk (General contact

${ }^{1}$ Associate Director, Advanced Space Concepts Laboratory

${ }^{2}$ Director, Advanced Space Concepts Laboratory
} 
electromagnetic energy from the Sun pushes the spacecraft and from Newton's second law momentum is transferred when the energy strikes and when it is reflected. The concept of solar sailing is thus the use of these quantum packets of energy, i.e. SRP, to propel a spacecraft, potentially providing a continuous acceleration limited only by the lifetime of the sail materials in the space environment. The momentum carried by individual photons is extremely small; at best a solar sail will experience $9 \mathrm{~N}$ of force per square kilometre of sail located in Earth orbit ( $\mathrm{M}^{\mathrm{c}}$ Innes, 1999), thus to provide a suitably large momentum transfer the sail is required to have a large surface area while maintaining as low a mass as possible. Adding the impulse due to incident and reflected photons it is found that the idealised thrust vector is directed normal to the surface of the sail, hence by controlling the orientation of the sail relative to the Sun orbital angular momentum can be gained or reduced. Using momentum change through reflecting such quantum packets of energy the sail slowly but continuously accelerates to accomplish a wide-range of potential missions.

The concept of solar sailing and the physics on which it is based can be traced back to the $17^{\text {th }}$ century. Subsequently, the concept of solar sailing was articulated as an engineering principle in the early $20^{\text {th }}$ century by several authors including the Father of Astronautics, Konstanty Ciołkowski, also Tsiolkovsky, along with Fridrikh Tsander and Herman Oberth (Tsiolkovsky, 1921; Tsander, 1924; Oberth, 1923). Following the initial work by Ciołkowski, Tsander and Oberth the concept of solar sailing appears to have remained largely dormant for over thirty years. However, as the concept reemerged in the middle of the $20^{\text {th }}$ century the term Solar Sailing was coined by Richard Garwin in the journal Jet Propulsion (Garwin, 1958). Through the latter half of the $20^{\text {th }}$ century and into the $21^{\text {st }}$ century a significant amount of both theoretical and practical work has been performed, considering the astrodynamics, mission applications and technology requirements of solar sailing.

Early comparisons of solar sailing with chemical and ion propulsion systems showed that solar sails could match or out perform these systems for a range of mission applications, though of course the level of assumed technology status is crucial in such comparisons (MacNeal, 1972). Furthermore, the lack of mission concepts limited such studies to exploration of the fundamental problems and benefits of solar sailing. One of the earliest solar sail mission concepts studied in detail was the NASA Comet Halley mission which required a launch in late 1981 or early 1982 to rendezvous with Comet Halley at its perihelion in the mid-1980's by spiralling towards the Sun and then changing the orbit inclination by almost 180 deg (Wright and Warmke, 1976).

Since the NASA Comet Halley mission studies a large number of solar sail mission concepts have been devised and promoted by solar sail proponents. As such, this range of mission applications and concepts enables technology requirements derivation and a technology application pull roadmap to be developed based on the key features of missions which are enabled, or significantly enhance, through solar sail propulsion.

\section{Performance Metrics}

To compare solar sail mission applications and concepts standard performance metrics will be used. The most common metric is the characteristic acceleration which is the idealised SRP acceleration experienced by the solar sail facing the Sun at a distance of 1 au. An ideal or perfect sail facing the Sun at a distance of 1 au will experience a pressure of $9.126 \mu \mathrm{N} \mathrm{m}^{-2}$; however, in practise an efficiency factor must be added to this to account for non-ideal performance (Wright, 1992). The sail characteristic acceleration offers an excellent performance metric unsullied by difficulties in hardware development and implementation of the theory. 
The sail assembly loading is the primary hardware performance metric for a solar sail, allowing a measure of the performance of the sail film and the efficiency of the solar sail architectural and structural design. The sail characteristic acceleration and assembly loading are defined as,

$$
a_{s_{c}}=\frac{2 P}{\sigma_{s}+\left(m_{a} / A\right)}, \quad \sigma_{s}=\frac{m_{s}}{A}
$$

where, $P$ is SRP acting on the solar sail, $m_{a}$ is mass attached to the solar sail, $m_{s}$ is mass of the solar sail and $A$ is the reflective surface area of the solar sail, typically assumed simply as the sail film area.

\section{Solar Sail Mission Catalogue}

In the final quarter of the $20^{\text {th }}$ century and opening decade of the $21^{\text {st }}$ century solar sail propulsion has been proposed for a diverse range of mission applications ranging throughout the solar system. However, in-order to develop an application-pull technology development roadmap the concepts which are truly enabled or significantly enhance by solar sail propulsion must be identified. As such the mission catalogue will initially consider a wide range of mission concepts to allow definition of key characteristics of missions which are truly enabled or significantly enhance by solar sail propulsion. Subsequently critical missions which can act as facilitators to later, more technologically complex missions will be discussed in further detail. Through these considerations a solar sail application-pull technology development roadmap is established, using each mission as a technology stepping-stone to the next.

\subsection{Identification of Key Characteristics}

To aid the identification of key characteristics solar sail applications are divided into the seven categories below.

\subsubsection{Planet-Centred and other Short Orbit Period Applications}

This category is essentially planet, minor-planet and small body centred trajectories. Planet-centred trajectory design has been largely restricted to escape manoeuvres or relatively simplistic orbit manoeuvring, such as lunar fly-by's or orbit inclination change (Eguchi et al, 1993; Fekete et al, 1992; Fimple, 1962; Green, 1977; Irving 1959; Lawden, 1958; Leipold, 1999; Macdonald \& M'Innes, 2005a, 2005b; Morgan, 1979; Pagel, 2002; Sackett, 1977; Sackett \& Edelbaum, 1978; Sands, 1961). Such trajectories place significant technology demands on the solar sail architecture as shown in Fig. 1 where a locally optimal energy gain control profile is shown for an Earth-centred orbit over a 3 day period starting approximately on the vernal equinox of the year 2000, to be exact Julian Day (JD) 2451624.5. The initial orbit in Fig. 1 is circular, with GEO radius and is placed, as close as possible, within the ecliptic plane, the sail characteristic acceleration is $1 \mathrm{~mm} \mathrm{~s}^{-2}$ and no orbit perturbations or shadow effects are included in the orbit propagation. From Fig. 1 it is seen that the sail control profile requires the sail to be rotated through 180 degrees once per orbit and then rapidly reset to maximise energy gain; as the sail size grows clearly this becomes an increasingly demanding technology requirement. It is noted that other simplistic orbit manoeuvres require similarly agile sail technology, for example an orbit plane-change require the sail to be rotated approximately $70.5 \mathrm{deg}$. twice per orbit (Macdonald, 2005a). This technology requirement for an agile sail is a significant disadvantage to the majority of short orbit period solar sail applications; however it should not be considered a blockage on the roadmap. 

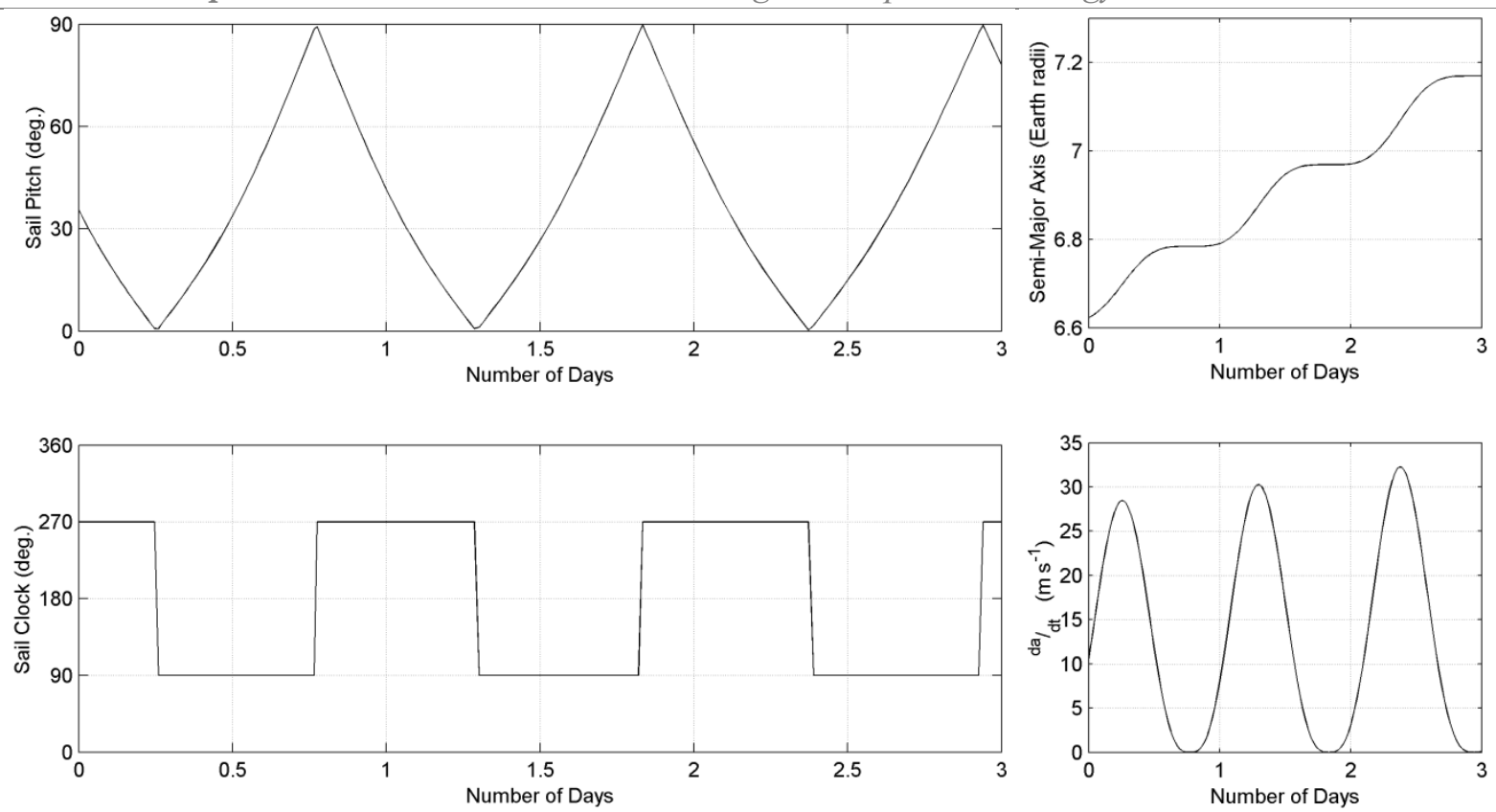

Fig. 1 Solar sail locally optimal energy gain control profile with resultant semi-major axis and rate of change. Sail pitch is limited to a 90 degree cone centred about the anti-Sun vector, the clock angle then rotates the vector about the cone.

Two highly significant planet-centred solar sail applications have been identified which do not require, but may in-practise desire, active sail control and hence do not require an agile sail; these are

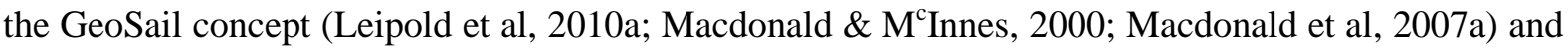
the Mercury Sun-Synchronous Orbiter (Leipold et al, 1996a, 1996b). These two solar sail mission concepts are very similar, both using a solar sail with fixed attitude to independently vary a single orbit parameter due to the orbits shape and alignment with the primary body, and the alignment to the Sun, creating a non-inertial orbit. GeoSail rotates the argument of perigee of an eccentric orbit within the ecliptic plane at approximately $1 \mathrm{deg}$ per day such that orbit apogee remains within the Earth's magnetotail. The Mercury Sun-Synchronous Orbiter meanwhile rotates the ascending node of an eccentric orbit whose orbit plane is at right-angles to the ecliptic plane such that the orbit plane remains perpendicular to the Sun-planet line, therefore enabling a Sun-synchronous orbit at Mercury which is not possible naturally due to the high reciprocal of flattening of the planet.

\subsubsection{Highly Non-Keplerian Orbit Applications}

This category is, in some regards, an extension of concept embodied by non-inertial orbits, with the sail providing a small but continuous acceleration to enable an otherwise unattainable or unsustainable observation outpost.

Interestingly, as early as 1929 Oberth, in a study of Earth orbiting reflectors for surface illumination (Oberth, 1929), noted that solar radiation pressure will displace a reflector in a polar orbit in the antiSun direction. Since then a significant volume of work has been performed in this area; a comprehensive review of Highly Non-Keplerian Orbits (NKO) has recently been completed by $\mathrm{M}^{\mathrm{c}}$ Kay et al (2011) in which a range of orbits and applications are presented. Highly NKOs are typically characterised as requiring a small but continuous acceleration in a fixed direction, in this case provided by a solar sail with fixed attitude to provide the thrust required to compensate for the differences in gravitation and rotational force (gravity gradient) to displace the spacecraft to an artificial equilibrium point at a location some distance from a natural libration point. 
Two primary solar sail applications of Highly NKOs are found in the literature; Geostorm and

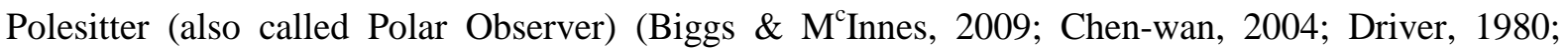

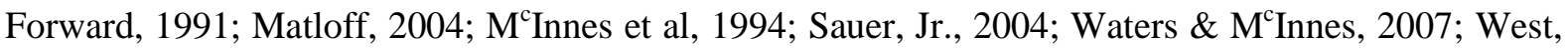
1996, 2000, 2004). The Geostorm mission concept provides real-time monitoring of solar activity; the spacecraft would operate sunward of the Earth's $L_{1}$ point, thus increasing the warning time for geomagnetic storms. By imparting a radial outward force from the Sun the solar radiation pressure ineffect reduces solar gravity and allows the $\mathrm{L}_{1}$ point to be moved sunward. As sail performance is increased solar gravity is further 'reduced', thus providing enhanced solar storm warning.

The Polesitter concept extends the Geostorm concept from a singular equilibrium point to derive equilibrium surfaces which extend out of the ecliptic plane and are again parameterised by the sail performance ( $\mathrm{M}^{\mathrm{c}}$ Innes et al, 1994). By extending the artificial equilibrium points out of the ecliptic plane, the small but continuous acceleration allows a spacecraft to be stationed above, or below, the second body within the 3-body problem. A further example of a highly non-keplerian orbit application is the Statite proposed by Forward (1991), which would use a high-performance solar sail to directly balance the solar gravity to hover stationary over the poles of the Sun.

The conceptually simple nature of the Geostorm and Polesitter missions is complicated by mission requirements, risk and budget factors and by the unstable nature of artificial equilibrium points.

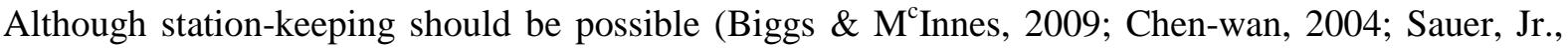
2004; Waters \& $M^{c}$ Innes, 2007) the requirement to station-keep increases the minimum level of technology requirement of the mission beyond, for example, the GeoSail mission discussed previously.

\subsubsection{Inner Solar System Rendezvous Missions}

This category covers missions which use the solar sail to rendezvous, and perhaps bound the orbit to, a body in the inner solar system; defined as all bodies from the asteroid belt inwards, specifically excluding bodies which are, in-effect, part of the Jupiter system, for example the Hilda and Jupiter Trojan asteroids.

The use of solar sails for high-energy sample return missions to the inner planets has been discussed extensively within the literature (Garner et al, 2001; Hughes, 2006; Leipold, 1999; McInnes et al, 2002; Sauer, Jr., 1976; Tsu, 1959; Vulpetti et al, 2008; Wright, 1992; Wright \& Warmke, 1976) often without presenting the trajectory as part of a larger system-level trade on the propulsion selection criteria. Solar sailing, like other forms of low-thrust propulsion, requires that if a bound orbit about the target body is desired then at arrival the spacecraft must have, in-effect, zero hyperbolic excess velocity. Therefore, any wholly low-thrust interplanetary mission is required, unlike high-thrust missions, to slow-down prior to arrival at the target body and subsequently the transfer duration is typically significantly increased; this is especially true for bodies which can be relatively easily reached by high-thrust, chemical propulsion systems such as Mars and Venus. Furthermore, once the solar sail has been captured into a bound-orbit about the target body it then has the typical disadvantages discussed previously for planet-centred solar sail applications.

A sequence of assessment studies was previously conducted by the Authors and Hughes looking at solar sail sample return missions to Mars ( $\mathrm{M}^{\mathrm{c}}$ Innes et al, 2003a), Venus ( $\mathrm{M}^{\mathrm{c}}$ Innes et al, 2003b),

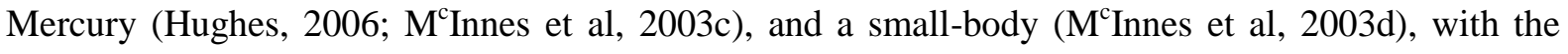
specific objective of enabling a system-level trade on the propulsion selection criteria within each mission. Within each of these a complete system level analysis was performed, considering a range of 
Preprint submitted a special issue of the journal

Advances in Space Research entitled "Solar Sailing: Concepts, Technology, Missions"

mission architectures, attempting to define the most preferential solar sail architecture. The identified preferential solar sail architecture was then compared against alternative propulsion systems conducting a similar mission.

In all Mars Sample Return mission architectures it was found to be very difficult to justify the use of a solar sail due to the significantly increased mission duration ( $\mathrm{M}^{\mathrm{c}}$ Innes et al, 2003a). The "grab-and$g o$ " architecture, identified as the most preferential for solar sailing required a mission duration of 5 6 years depending on the launch vehicle, while a similar all chemical propulsion mission could be completed in only 2 years, although requiring a slightly larger launch vehicle ( $\mathrm{M}^{\mathrm{c}}$ Innes et al, 2003a). A very similar scenario was found in the analysis of the Venus Sample Return mission ( $\mathrm{M}^{\mathrm{c}}$ Innes et al, 2003b). However, it was found that due to the increased launch mass sensitivity to returned mass the use of a solar sail for the Earth return stage offered potential real benefits; note the solar sail attached mass for this scenario was $323 \mathrm{~kg}$ requiring a sail of less than $100-\mathrm{m}$ side length at an assembly loading of $6 \mathrm{gm}^{-2}$, with $20 \%$ design margin. It was found that using a solar sail for the Earth return stage of a Venus Sample Return mission reduced the launch mass by approximately $700 \mathrm{~kg}$, enabling a smaller, hence lower cost, launch vehicle to be used without notably impacting mission duration. Such a scenario does however have the typical disadvantages discussed previously for planet-centred solar sail applications when using the sail to escape the Venus gravity-well.

Considering both the Mercury and Small Body Sample Return missions it was found that due to the high-energy nature of the transfer trajectories only low-thrust propulsion systems offered viable mission concepts, with solar sailing offering potential benefits (Hughes, 2006; $\mathrm{M}^{\mathrm{c}} \mathrm{Innes}$ et al, 2003c, 2003d). Note the small-body target was asteroid 2001 QP153, with an orbit inclination of $50 \mathrm{deg}$. The Mercury Sample Return mission would have the typical disadvantages discussed previously for Short Orbit Period solar sail applications, however it was found that a large, high-performance solar sail would offer some potential benefits to such a mission (Hughes, 2006). It is of note that missions to small bodies, such as asteroid 2001 QP153, could negate the disadvantages discussed previously for short orbit period solar sail applications as the sail may not be required to enter a bound orbit about the small-body, if indeed a stable orbit could even be found.

\subsubsection{Outer Solar System Rendezvous Missions}

The use of solar sails for outer solar system rendezvous missions has been long discussed within the literature (Garner et al, 2001; Leipold, 1999; Wright, 1992; Wright \& Warmke, 1976). Furthermore, an assessment study was previously conducted by the Authors and Hughes looking at a range of solar sail Jupiter missions ( $M^{c}$ Innes et al, 2003e, 2004a), including concepts for exploration of the Galilean moons. As with low-thrust inner solar system rendezvous missions the hyperbolic excess velocity at the target outer solar system body must be lower than high-thrust missions. The inverse squared variation in SRP with solar distance however means that the sail performance is significantly reduced over the same sail at Earth. As such the requirement to reduce the hyperbolic excess velocity prior to arrival at the outer solar system body leads to prolonged transfer durations. Note however that due to the large moons within both the Jupiter and Saturn planetary systems capture can be performed using gravity assist manoeuvres to enable the hyperbolic excess velocity to be significantly greater than zero (Macdonald, 2005c).

Furthermore, the duration required to reduce the orbit altitude following capture is also significantly prolonged due to the inverse squared variation in SRP with solar distance. Clearly, this class of mission becomes increasingly unattractive as the target body moves further from the Sun. 
Briefly further considering the scenario of a Galilean moons mission, specifically Europa, it is noted that in addition to being very deep within the Jovian gravity well, Europa is also deep within the intense radiation belts found at Jupiter. The combination of low-thrust and high radiation requires significant shielding material, thus resulting in a heavy spacecraft unsuitable for solar sail propulsion.

Outer solar system rendezvous missions are concluded to be unsuitable for solar sail propulsion due to the inverse squared variation in SRP with solar distance.

\subsubsection{Outer Solar System Flyby Missions}

Outer solar system fly-by missions remove the requirement to reduce the hyperbolic excess velocity prior to arrival at the target body and as such negate much of the negative elements of solar sail outer solar system rendezvous missions. A Jupiter atmospheric probe mission was considered by the Authors and Hughes ( $\mathrm{M}^{\mathrm{c}}$ Innes et al, 2003e) as a potential Jupiter flyby mission. It was concluded that due to the mass of the atmospheric probes, of which three were required, and the relative ease of such a mission with chemical propulsion that solar sail propulsion offered little to such a mission. It is of note that as the target flyby body moves further from the Sun, and hence the difficulty of such a mission with chemical or solar electric propulsion (SEP) increases, solar sail propulsion becomes increasingly beneficial; ultimately leading to a peak in solar sail benefits for such missions in the Beyond Neptune category which will be discussed later.

\subsubsection{Solar Missions}

Most previous missions to study the Sun have been restricted to observations from within the ecliptic. The Ulysses spacecraft used a Jupiter gravity assist to pass over the solar poles, obtaining field and particle measurements but no images of the poles. ${ }^{\dagger}$ Furthermore, the Ulysses orbit is highly elliptical, with a pole revisit time of approximately 6 years. It is desired that future solar analysis be performed much closer to the Sun, as well as from an out-of-ecliptic perspective. The Cosmic Visions mission concept Solar Orbiter intends to deliver a science suite of order $180 \mathrm{~kg}$ to a maximum inclination of order $35 \mathrm{deg}$ with respect to the solar equator and to a minimum solar approach radius of $0.22 \mathrm{au}$ using SEP. The inability of the Solar Orbiter mission to attain a solar polar orbit highlights the difficulty of such a goal with conventional propulsion. It has however been shown that a mid-term solar sail can be used to deliver a spacecraft to a true solar polar orbit in approximately five-years (Goldstein et al, 1998; Macdonald et al, 2006). The Solar Polar Orbiter (SPO) mission concept is a good example of the type of high-energy inner-solar system mission which is enabled by solar sail propulsion.

\subsubsection{Beyond Neptune}

A significant quantity of work in the past decade has been performed to assess the problem of trajectory and system design of a solar sail mission beyond Neptune (Colasurdo \& Casalino, 2001; Dachwald, 2004a, 2004b, 2005; Garner et al, 2000, 2001; Leipold \& Wagner, 1998; Leipold, 1999;

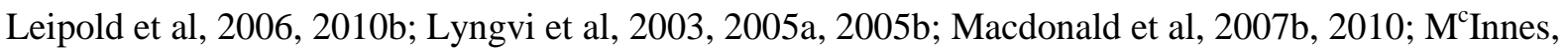
2004a; MInnes et al, 2004b; Sauer, Jr., 2000; Sharma \& Scheeres, 2004; Sweetser \& Sauer, Jr., 2001; Vulpetti, 1997, 2002; Wallace, 1999; Wallace et al, 2000; West, 1998; Yen, 2001). It has been shown

\footnotetext{
† "Ulysses," ESA Science and Technology, URL: http://sci.esa.int/science-e/www/area/index.cfm?fareaid=11 [cited 21 May 2010].

* “Solar Orbiter," ESA Science and Technology, URL: http://sci.esa.int/solarorbiter [cited 21 May 2010].
} 
that solar sail propulsion offers significant benefits to missions concepts which aim to deliver a spacecraft beyond Neptune, for either a Kuiper Belt or Interstellar Heliopause (at approximately 200 au) mission. Such outer solar system missions initially exploit the inverse squared variation in SRP with solar distance by approaching the Sun to gain a rapid energy boast which generates a hyperbolic trajectory and allows the spacecraft to rapidly escape the solar system.

Solar sails mission concepts significantly beyond the interstellar Heliopause were considered by Macdonald et al (2010). In-order to determine the limit of the solar sail concept an Oort cloud mission was examined using solely SRP to propel the spacecraft. It was found that although no fundamental reason existed why such a mission may not be possible the practicalities were such that the Interstellar Heliopause Probe (IHP) mission concept could be considered representative of the upper limiting bound of the solar sail concept.

\subsubsection{Key Characteristics}

Solar sailing has traditionally been perceived as an enabling technology for high-energy missions; however, as has been shown in the preceding sections the key characteristics of a mission which is enabled, or significantly enhanced by solar sailing are more complex than simply this.

Solar sailing is, due to the lack of propellant mass, often noted as reducing the launch mass of an equivalent chemical or SEP concept, which is in-turn noted as reducing launch and mission cost. However, while it is accurate that the launch mass is typically reduced this does not directly result in a reduced launch vehicle cost as the reduction may not be sufficient to allow the use of a less capable, and hence lower cost, launch vehicle. As such the launch cost is only reduced if the reduced launch mass allows a smaller launch vehicle to be used, meaning that launch cost varies as a step function while launch mass linearly increases. Finally, it should be noted that if the total mission cost is high, say, 500+ M€ then reducing the launch mass cost by $10-20 \mathrm{M} €$ is a cost saving of order $2-4 \%$, which may not be considered a good cost/risk ratio for the project and indeed, the cost saving may be insufficient to pay for the additional development of the technology. Thus for the reduction in launch mass to be an enabling, or significantly enhancing aspect of a solar sail mission concept the cost saving must also be a significant percentage of the total mission cost.

The most significant distinguishing characteristic between all solar sail mission concepts are those which use the sail to reach a high-energy target and after which the sail can be jettisoned by the spacecraft, for example the Solar Polar Orbiter mission. And, mission concepts which require the solar sail to maintain a novel or otherwise unsustainable observation outpost, for example, highly nonkeplerian or non-inertial orbit applications, such as Geostorm and GeoSail. This distinction is important as the later compares very favourably against most other propulsion systems, especially as the mission duration and hence reaction mass is increased. However, a solar sail is a very large structure and could adversely impact the mission objectives either through a characteristically low pointing accuracy due to low frequency structural flexing, or due to the solar sail interfering with the local environment in, for example, particle and field measurements. Thus, a critical requirement on early solar sail demonstration missions must be to validate the simulated pointing accuracy of the platform and the effect of the sail on the local space environment. Solar sail mission concepts are therefore sub-divided into two classes, these are:

- Class One

$\bigcirc$ Where the solar sail is used to reach a high-energy target and after which the sail can be jettisoned by the spacecraft, for example the Solar Polar Orbiter mission. 
- Class Two

- Where the solar sail is required to maintain a novel or otherwise unsustainable observation outpost, for example, highly non-keplerian or non-inertial orbit applications, such as Geostorm and GeoSail.

From the mission catalogue it is seen that solar sail propulsion has been considered for a large range of mission applications, some of which it is more suitable for than others. Each of the solar sail applications within the mission catalogue are sub-divided by mission class and the level of enhancement offered by solar sail propulsion in Table 1 . From Table 1 the key positive and negative characteristics of solar sail missions are defined in Table 2.

Table 1 Solar sail missions by benefit

\begin{tabular}{|c|c|c|c|c|c|}
\hline \multicolumn{2}{|r|}{$\begin{array}{c}\text { Enabled or Significantly } \\
\text { Enhance }\end{array}$} & \multicolumn{2}{|r|}{ Marginal benefit } & \multicolumn{2}{|r|}{ No benefit } \\
\hline \multirow{2}{*}{ 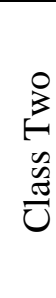 } & $\begin{array}{l}\text { Non-Inertial Orbits, such as } \\
\text { GeoSail or a Mercury Sun- } \\
\text { Synchronous Orbiter }\end{array}$ & \multirow{5}{*}{$\begin{array}{l}0 \\
0 \\
0 \\
\tilde{\Xi} \\
\tilde{\Xi}\end{array}$} & $\begin{array}{l}\text { Venus escape at end of } \\
\text { sample return mission }\end{array}$ & \multirow{5}{*}{$\begin{array}{l}\mathscr{\Xi} \\
0 \\
\infty \\
\tilde{\Xi} \\
\tilde{U}\end{array}$} & $\begin{array}{l}\text { Planetary escape at start } \\
\text { of mission }\end{array}$ \\
\hline & $\begin{array}{l}\text { Highly Non-Keplerian Orbits } \\
\text { such as Geostorm and } \\
\text { Polesitter }\end{array}$ & & $\begin{array}{l}\text { Mercury and high-energy } \\
\text { small body Sample Return } \\
\text { missions }\end{array}$ & & Mars missions \\
\hline \multirow{3}{*}{$\begin{array}{l}0 \\
0 \\
\tilde{y} \\
\frac{\tilde{\sigma}}{U}\end{array}$} & Kuiper-Belt fly-through & & $\begin{array}{l}\text { Outer solar system planet } \\
\text { fly-by }\end{array}$ & & $\begin{array}{l}\text { Outer solar system } \\
\text { rendezvous and centred } \\
\text { trajectories }\end{array}$ \\
\hline & Solar Polar Orbiter & & $\begin{array}{l}\text { Transit of Gravitational } \\
\text { Lens region }\end{array}$ & & \multirow[t]{2}{*}{$\begin{array}{l}\text { Loiter at the Gravitational } \\
\text { Lens }\end{array}$} \\
\hline & Interstellar Heliopause Probe & & Oort Cloud & & \\
\hline
\end{tabular}

Table 2 Solar sail mission key characteristics

\begin{tabular}{l|l}
\hline Positive Characteristic & Negative Characteristic \\
\hline Very High Energy transfer trajectory & Mars and Venus rendezvous \\
Inner Solar System & Outer Solar System rendezvous \\
Highly Non-Keplerian and Non-Inertial orbits & Short orbit period with rapid slew manoeuvres \\
Final stage in a multi-stage system & High radiation environment \\
Fly-by beyond the orbit of Neptune & High pointing stability required \\
& Required to rendezvous with a passive body \\
& Fly-by beyond solar gravitational lens \\
\hline
\end{tabular}




\subsection{Key Missions}

Three key mission will be briefly discussed, one from each of near, mid and far term.

\subsubsection{Near-Term: GeoSail}

The GeoSail mission concept is motivated by the desire to achieve long residence times in the Earth's magnetotail, enabling high resolution statistical characterisation of the plasma in a region subject to a variety of external solar wind conditions (Alexander et al, 2002; Leipold et al, 2010a; Macdonald et

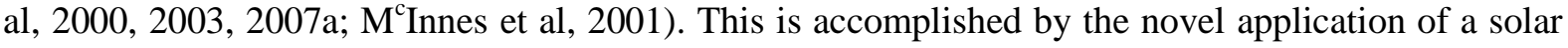
sail propulsion system to precess an elliptical Earth-centred orbit, interior to the lunar orbit, at a rate designed to match the rotation of the geomagnetic tail, the orientation of which is governed by the Sun-Earth line. The GeoSail mission concept is one of the earliest possible solar sail missions which can satisfy a clearly defined science requirement while also acting as a pathfinder to later, more technically demanding missions.

The first true solar sail mission must not be an experiment but a demonstration which, through its heritage, enables more technically demanding missions. Considering GeoSail as a potential technology demonstration mission it is required to resolve known issues and validate simulations and prior experiments. The first solar sail mission is required during sail deployment to observed and measure:

- Management and behaviour of the packaged film during deployment.

- Controlled release of film and booms.

- Film tension, boom loading and structural characteristics.

Following sail deployment, the stability, controllability and operational capability of a solar sail must be demonstrated through:

- Demonstration of measurable propulsive performance (apse-line rotation in GeoSail).

- Verification of attitude control models, concepts and operations.

- Demonstration of sufficient sail slew rate capability for future missions with no, or negligible, propellant expenditure.

- Verification of trajectory control algorithms.

Furthermore, test-ground model validation must be performed, such as to confirm predicted structural frequencies, sail performance degradation and sail force models (at a range of sail pitch angles). The navigation and guidance of a sail must also be demonstrated. The measurement of parameters which are difficult to measure / predict on the ground must be performed, such as:

- Analysis of response to thermal environment.

- Attitude perturbations due to uncontrollable variations in sail shape and performance degradation.

- Actual sail performance, resulting from actual sail shape and optical surface performance degradation.

- Actual sail pointing / stability capability.

In addition to the above sail deployment and control goals, measurement and analysis must be performed as to the effect of the sail on the local space environment. This is a key mission goal. The final engineering goal of GeoSail, or any sail demonstration mission, must be the successful 
demonstration of a sail jettison and separation manoeuvre; a key requirement of several solar sail missions such as the Solar Polar Orbiter and the Interstellar Heliopause Probe.

The GeoSail orbit has a perigee located above the planetary dayside at approximately 11 Earth radii $\left(\mathrm{R}_{\mathrm{E}}\right)$, corresponding to alignment with the magnetopause. Apogee is aligned with the geomagnetic tail reconnection region on the night-side of the Earth, at $23 \mathrm{R}_{\mathrm{E}}$. The orbit plane is within the ecliptic plane. The GeoSail orbit orientation is illustrated in Fig. 2, where it is seen that the Sun-Earth line is coincident with the orbit major axis. Note from Fig. 2 that the spacecraft will experience a prolonged Earth shadow event every apogee due to the required orbit orientation. With the spacecraft located in the ecliptic plane the sail normal is fixed at zero pitch, i.e. the sail is face-on to the Sun at all times, to induce the desired independent secular variation in the argument of pericentre ( $\mathrm{M}^{\mathrm{c}}$ Innes et al, 2001). Thus, by varying the sail thrust magnitude the rate of change of argument of pericentre can be varied. The required sail characteristic acceleration is found to be $0.09985 \mathrm{~mm} \mathrm{~s}^{-2}$; note the defined sail characteristic acceleration is adjusted to account for the prolonged shadow event each orbit. It is found that a square solar sail of order forty metres per side is required to conduct the GeoSail mission at an assembly loading of $34 \mathrm{~g} \mathrm{~m}^{-2}$, using $3.5 \mu \mathrm{m}$ Teonex ${ }^{\circledR}$ film and a boom specific mass of $40 \mathrm{gm}^{-1}$ (Macdonald et al, 2007a). However, it was also found that for the GeoSail mission to provide sufficient heritage to later, more technically demanding missions, the design point was required to be more demanding than should the GeoSail mission be conducted in isolation. It is noted finally that the GeoSail orbit is well suited to a technology demonstration mission due to its proximity to Earth, allowing extended observation of the system from Earth.

In direct comparison of solar sail, SEP and chemical variants of the GeoSail concept it is found that a high-thrust mission has an annual $\Delta v$ requirement of over $2 \mathrm{~km} \mathrm{~s}^{-1}$, resulting in significant difficulties when attempting to perform mission durations of longer than approximately one-year. Conversely it is found that a SEP variant is rather attractive as the required thrust level is easily attainable with current technology. It is of note that the exhaust gases would need to be neutralised, especially for a geomagnetic tail mission, as the ionised particles would interfere with science measurements and spacecraft subsystems, this adversely impacts the propellant mass required. It is found that a SEP variant of GeoSail could have a nominal duration of at least two-years (Macdonald et al, 2007a). Therefore, the solar sail mission is increasingly attractive for increased mission durations. It is also of note that the solar sail mission was found to fit with a Vega launch vehicle, while the SEP variant just tipped into a Soyuz vehicle, hence incurring a notable launch cost increase.

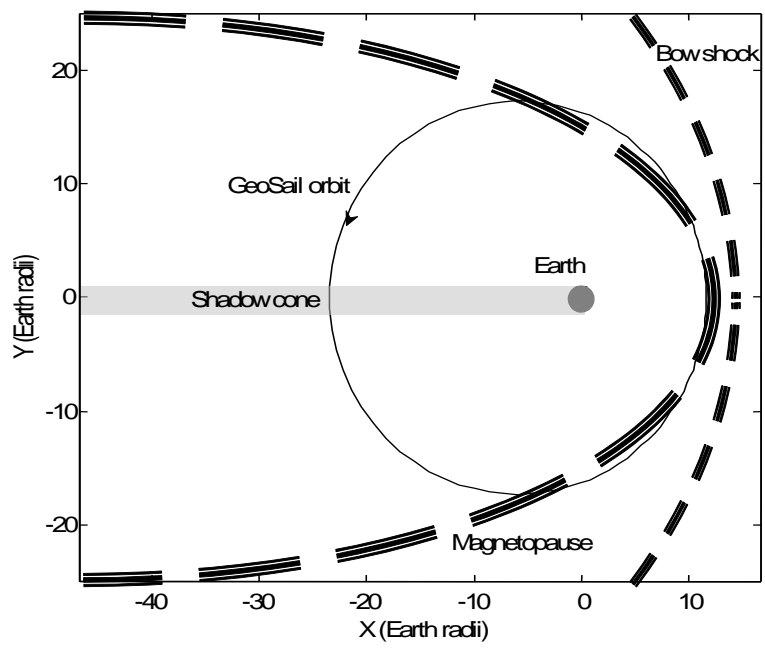

Fig. 2 GeoSail orbit illustration in rotating reference frame, with magnetosphere detailed 


\subsubsection{Medium-Term: Solar Polar Orbiter}

The Solar Polar Orbiter (SPO) mission concept is motivated by the desire to achieve high latitude, close proximity observations of the Sun. Terrestrial observations of the Sun are restricted to the ecliptic plane and within the solar limb, thus restricting observations to within $\pm 7.25 \mathrm{deg}$ of the solar equator. As discussed earlier the Ulysses spacecraft used a Jupiter gravity assist to pass over the solar poles, obtaining field and particle measurements but no images of the poles, however the orbit is highly elliptical, with a pole revisit time of approximately 6 years. It is desired that future solar analysis be performed much closer to the Sun, as well as from an out-of-ecliptic perspective, this is the goal of the Cosmic Visions mission concept Solar Orbiter. However, the inability of the Solar Orbiter mission to attain a solar polar orbit highlights the difficulty of such a goal with conventional propulsion. The SPO mission uses a solar sail to place a spacecraft into an orbit at 90 deg inclination with respect to the solar equator (82.75 deg with respect to the ecliptic plane) and interior to the Earth's orbit. Additionally, the spacecraft orbit is phased such that it will remain near to the solar limb from a terrestrial perspective which eliminates solar conjunctions and hence loss of telemetry. Once the solar sail has delivered the spacecraft to the solar polar orbit it is jettisoned to allow the science phase of the mission to begin (Goldstein et al, 1998; Macdonald et al, 2006).

The third resonant orbit is defined as the target orbit as this places the spacecraft close to the Sun, while also being in a relatively benign thermal environment compared to higher order resonant orbits. The SPO orbit is detailed in Fig. 3.

a)

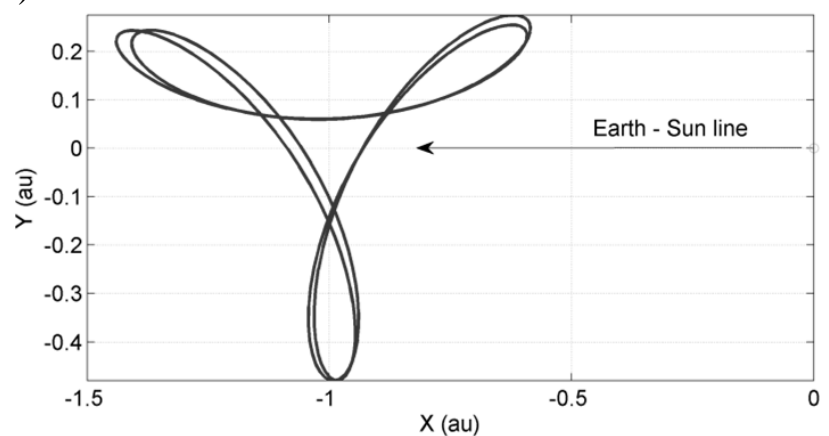

c)

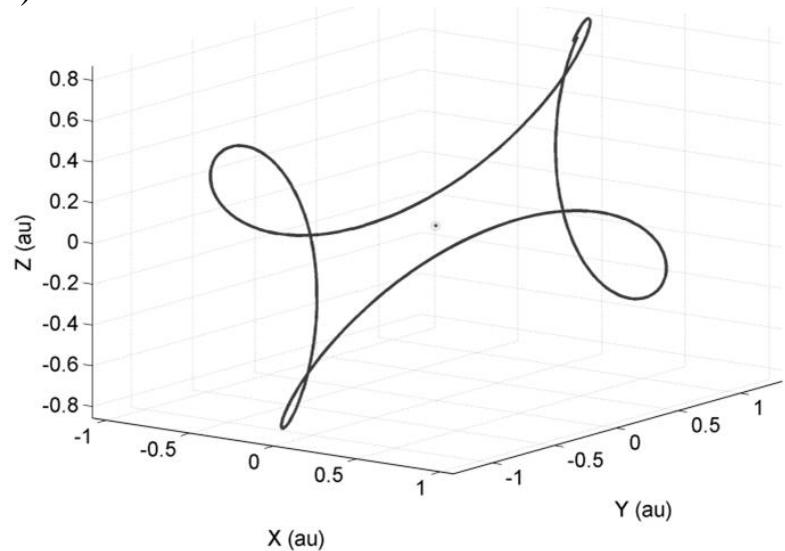

b)

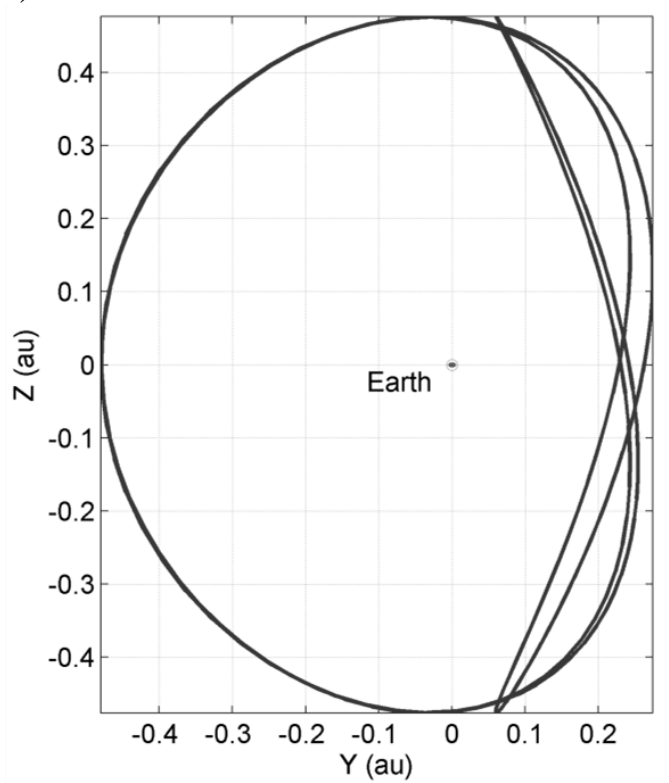

Fig. 3 Third resonant Earth orbit used by SPO in Earth-centred co-ordinates; a) \& b) Fixed Sun line along x-axis, c) Earth-centred inertial co-ordinate system 
Macdonald et al (2006) conducted an analysis to determine the minimum required slew rate of the solar sail within the SPO mission. It was considered that during the orbit inclination increase phase of the trajectory, or the cranking phase, the sail pitch is fixed at $\arctan \left(1 / \sqrt{2}_{2}\right)$, while the sail clock angle flips from $0 \mathrm{deg}$ to $180 \mathrm{deg}$, however it is clear that the sail thrust vector cannot be rotated through approximately $70.5 \mathrm{deg}$ instantaneously. Thus, the effect of variations in the sail slew rate on the cranking phase were quantified, concluding that a sail slew rate of $10 \mathrm{deg}$ per day $\left(10^{-4} \mathrm{deg} \mathrm{s}^{-1}\right)$ resulted in a performance degradation from the instantaneous slew of less than $0.5 \%$. A required sail slew rate of 10 deg per day was thus defined for the mission.

It is found that a square solar sail of order one-hundred and fifty metres per side is required to conduct the SPO mission at an assembly loading of $8 \mathrm{~g} \mathrm{~m}^{-2}$ and characteristic acceleration $0.5 \mathrm{~mm} \mathrm{~s}$ (Macdonald et al, 2006). Macdonald et al (2006) concluded that both conventional SEP and chemical propulsion could not be considered viable alternatives to solar sailing for an SPO mission. As such a comparison against new and novel propulsion systems was conducted, such as nuclear electric propulsion (NEP), radioisotope electric propulsion (REP) and Mini-Magnetospheric Plasma Propulsion (M2P2). It was expected that any NEP system will require a large launch vehicle due to the inherent nature of the system. Meanwhile, the use of a REP system would require extremely advanced radioisotope power sources to compete with solar power. M2P2 could potentially provide the required change in velocity needed to attain a true solar polar orbit. This concept is akin to solar sails, but has the advantage of not requiring large structures to be deployed. The drawback to this propulsion method is that the magnetic field generating system mass may be quite high. The lack of viable competing propulsion systems serves to highlight the potential of solar sailing for a solar polar mission concept. It is thus conclude that solar sailing offers great potential for this mission concept and indeed may represent the first useful deep space application of solar sail propulsion.

\subsubsection{Far-Term: Interstellar Heliopause Probe}

As previously discussed a significant quantity of work in the past decade has been performed to assess the problem of trajectory and system design of a solar sail mission beyond Neptune. A specific example of this class of mission is the Interstellar Heliopause Probe (IHP) concept which exploits the inverse squared variation in SRP with solar distance by approaching the Sun to gain a rapid energy boast which generates a hyperbolic trajectory and allows the spacecraft to rapidly transit the inner solar system prior to sail jettison at $5 \mathrm{au}$.

The IHP mission concept typically envisages the spacecraft arriving at a solar distance of 200 au in $15-25$ years. The issue of an upper feasible limit on mission duration is difficult to quantify. For example, the Voyager spacecraft remain operational over three-decades since launch, yet the primary mission of these spacecraft was, approximately, three and twelve years for Voyager 1 and 2 respectively. However, both spacecraft have continued to provide scientifically interesting data and as such operations have continued. Typically any IHP mission would provide continuous science data from $5 \mathrm{AU}$ onwards, i.e. post-sail jettison, thus it is anticipated that the spacecraft will provide scientifically interesting data from an early stage. However, the primary goal of the mission is measurement of the interstellar medium, which therefore necessitates a funding commitment over a much longer period than originally envisaged for the Voyager spacecraft. Clearly the perceived upper feasible limit on mission duration has a significant impact on the required technology of the mission concept. It is of interest that previous NASA led activities have targeted a solar distance of 200 au in 15 years (Garner et al, 2000; Wallace, 1999; Wallace et al, 2000), while recent ESA and European activities have typically targeted a solar distance of 200 au in 25 years (Leipold et al, 2010b; Lyngvi 
Preprint submitted a special issue of the journal

Advances in Space Research entitled "Solar Sailing: Concepts, Technology, Missions"

et al, 2003, 2005a, 2005b; Macdonald et al, 2007b, 2010). The NASA led activities clearly determine that a conventional square solar sail will not suffice for the short mission duration and that a spinning disc sail, or some other equally low sail assembly loading sail architecture, is required. However, the European studies exhibit some ambiguity on the required sail technology level which was recently considered by Macdonald et al who concluded that the ambiguity was perhaps due to a slight relaxation in the mission duration requirement (2010).

It is found that a disc solar sail of order one-hundred and fifty to two-hundred metres radius is required to conduct the IHP mission at an assembly loading of $1.5-2 \mathrm{~g} \mathrm{~m}^{-2}$, delivering a characteristic acceleration of $1.5-3 \mathrm{~mm} \mathrm{~s}^{-2}$ (Macdonald et al, 2010; Wallace et al, 2000). It can be shown that a chemical IHP mission is feasible, however to provide a similar trip time it requires a heavy-lift launch vehicle and an Earth-Jupiter gravity assist trajectory which significantly limits the launch window opportunities. Note, the solar sail launch window repeats annually (Macdonald et al, 2010). Conventional chemical propulsion for the IHP mission appears unattractive from this concept, however should a specific impulse of over 450 seconds be achieved then such a variant, with a large burn at 4 solar radius may be possible from a Soyuz-like launch vehicle ( $M^{c}$ Innes et al, 2004b). The use of SEP is possible, again using a gravity assist trajectory; however, it is unlikely that a solar power system would be sufficient for a IHP mission. NEP is however an attractive option for the IHP mission and could be used to reduce trip time and launch mass over most other options, there will however be a limit to this launch mass reduction as the smallest fission reactor and engine size is likely to be of order $1200 \mathrm{~kg}$ (M'Innes et al, 2004b). A major advantage of using NEP is that the reactor can be used to provide a power-rich spacecraft at 200 au and so provide high data rates through a modest high-gain antenna. The primary disadvantage of the NEP concept, beyond the attendant political issues, is that the spacecraft may be required to continue thrusting beyond the orbit of Jupiter to reach 200 au in the required timeframe. Continued thrusting may adversely impact the science objectives of the mission with a direct consequence for funding. Finally, M2P2 and electric sail technology may both offer interesting alternatives to solar sailing (Janhunen, 2008; Winglee et al, 2000).

\section{Application Pull Technology Development Route}

Considering the IHP mission as typical of the culmination of any solar sail application roadmap it is important that the technology requirements of this mission application be enabled by previous milestones on the roadmap, that is to say, previous missions. Hence, as the IHP mission requires a low sail assembly loading sail architecture it is critical that previous applications of solar sailing provide suitable heritage to this mission. The top-level technology requirements of each of the missions from within the catalogue, which satisfy the positive criteria detailed in Table 2, are shown in Fig. 4. It should be noted that Fig. 4, is independent of sail architecture as it simply relates the required sail surface area to the required sail assembly loading.

Each of the key missions discussed in Section 0 can be seen within Fig. 4. It is noted that despite, as discussed in Section 3.2.1, the GeoSail system analysis being over-engineered if the mission were conducted in isolation, rather than as part of a technology development roadmap, the GeoSail technology requirements still do not clearly fit within the application technology requirement bounds of the more demanding mission concepts. Indeed, for GeoSail to provide a simple log-linear technology trend towards the two other key missions discussed in Section 0 the sail assembly loading must be further reduced to approximately $20-25 \mathrm{~g} \mathrm{~m}^{-2}$, while to reach the Mean Application Trend the sail assembly loading must be further reduced to approximately $15-20 \mathrm{~g} \mathrm{~m}^{-2}$. 


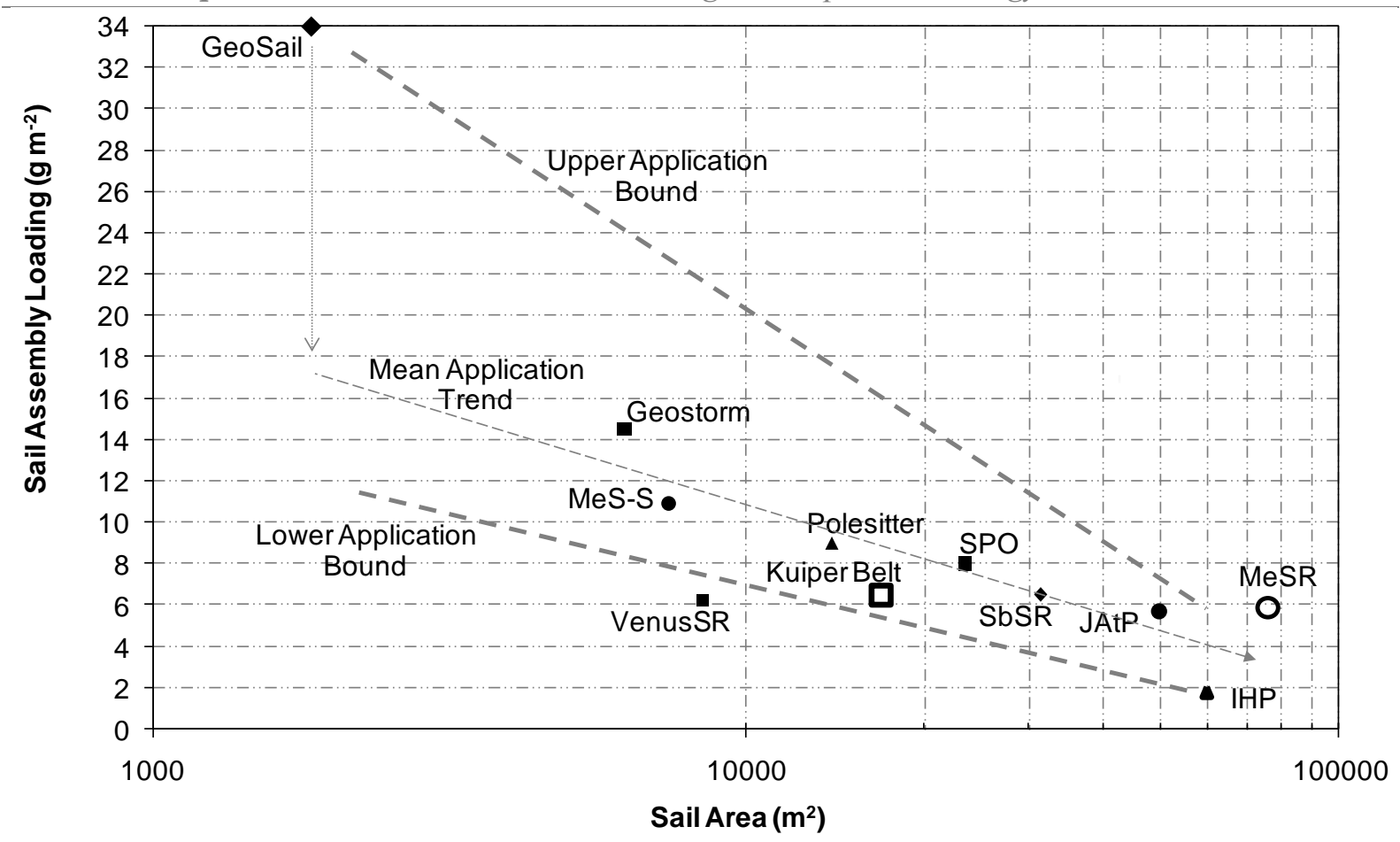

Fig. 4 Solar sail mission catalogue application technology requirements. IHP $\equiv$ Interstellar Heliopause Probe; JAtP $\equiv$

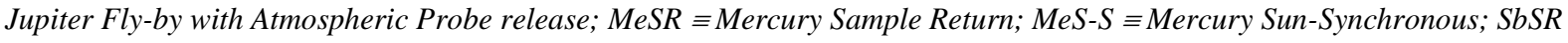

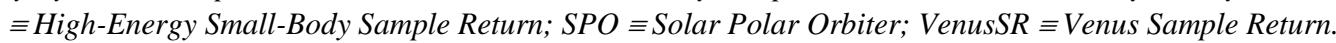

\section{Future Advancement Roadmap}

The currently identified science applications of solar sailing which will, due to the enabling or significantly enhancing aspects of solar sail propulsion, pull the technology development are, as seen in Fig. 4, significantly clustered about the mid to far-term technology; while the near-term remains sparsely populated. There can be little argument about the scientific value of missions such as SPO. However, the risk involved in directly attempting such a mission with solar sail propulsion would be so large as to be prohibitive.

Solar sailing is an elegant concept, however it must be pulled forward by mission applications at the same time as it is pushed by technology development. This also holds true for initial flight tests of solar sailing. As discussed in Section 3.2.1, unless such flight tests provide confidence in the technology and a clear path towards some enabling capability, they will not perform a useful function. A good example of this was the use of low cost sounding rockets by ISAS (now JAXA) to test multiple sail deployment mechanisms during the short period of free-fall which allowed for several tests of scaled prototypes at the same cost as a single launch to orbit. By spreading the risk over several tests the inevitable unforeseen single point failures of deployment could be identified prior to launch of IKAROS in May 2010 as a full-scale demonstration mission (Mori et al, 2010; Normile, 2010; Sawada et al, 2010).

With the clearly established clustering of identified enabling or significantly enhancing applications of solar sailing towards the mid to far-term a requirement exists to backfill these requirements. This can be achieved in two ways, the first of which is to develop new mission concepts which are enabling or significantly enhancing by near-term solar sail propulsion in a similar way to the GeoSail concept. The alternative to this is to consider the problem from an engineering perspective and to reengineer the mission concepts and the vision of the future of solar sailing, such that the gap between 
near and mid-term applications is removed. This can be achieved by recognising and adapting the Advancement Degree of Difficulty (AD2) scale ${ }^{\S}$. Technology Readiness Levels (TRLs) define the maturity, or readiness, at discrete points in a schedule. However, this is only half of the engineer's problem. TRLs provide no information on how well, or easily, the technology will move from one TRL to the next, i.e. what is the risk of the technology development program. The AD2 scale was developed to address issues of programmatic risk and to aid the incorporation of low-TRL components into larger systems, however the founding principles can be adapted to larger scale, novel or advanced concepts such as solar sailing. The AD2 scale categorises risk from the lowest AD2, Level 1 (0\% risk) defined as "Exists with no or only minor modifications being required. A single development approach is adequate." Through to the highest AD2, level 9 (90-100\% risk), defined as "Requires new development outside of any existing experience base. No viable approaches exist that can be pursued with any degree of confidence. Basic research in key areas needed before feasible approaches can be defined." Performing a simple, top-level AD2, TRL project status analysis of solar sailing for an advanced technology demonstrator it is found that the project risk is, at best, acceptable, and that dual development approaches should be pursued to increase confidence.

\subsection{Disruption by Evolution}

To reduce the risk on the solar sail development roadmap the AD2 level must be reduced. This can be done in two ways, firstly by considering solar sailing as a primary propulsion source an extension of the use of solar sailing as an attitude control device and secondly by incorporating other low-thrust, high TRL propulsion technologies into the early solar sail technology development roadmap to bridge the gap between the near and mid-term applications, i.e. hybrid sail/SEP propulsion.

The use of SRP for attitude control on large spacecraft in geostationary orbit and interplanetary space is common practise. Most notably, Mariner 10 used a small "kite" $(31 \mathrm{~cm} \times 76 \mathrm{~cm})$ for manoeuvring by using the pressure of sunlight for attitude control. By using the ballast solar sail for attitude control manoeuvring the Mariner 10 project was able to extend the planned life of the mission and increase mission science returns (NASA/JPL, 1975, 1976; Shirley, 2002). A similar technique was employed by the MESSENGER mission to Mercury. The principles of solar sailing are thus already at a high TRL. The inherent programmatic risk in solar sailing is a direct result of the high AD2 in progressing immediately to a spacecraft using SRP as the sole primary propulsion system. The programmatic risk in solar sailing can be significantly reduced by hybridising the propulsion with a high TRL SEP system, which also offers critical advantages when considering trajectory generation due to the ability of an SEP system to thrust directly towards the Sun. The Mariner 10 and MESSENGER spacecraft both used a rather small kite, or solar sail, and there is no reason why other inner solar system missions would not similarly benefit from doing so. In this regard such missions would be primarily a SEP spacecraft which also has a small solar sail. The AD2 is then significantly reduced when incrementally reducing the size of the SEP system and increasing the size of the solar sail as its TRL is increased.

Through propulsion hybridisation it can be expected that the mid to far-term cluster of solar sail applications seen in Fig. 4 will either, for the same scientific product quality, shift down the sail area axis towards the near-term, therefore reducing the AD2 of concepts such as SPO, or provide an enhanced scientific product quality. For example, considering the Geostorm mission concept, it is

\footnotetext{
${ }^{\S}$ See http://jbconsultinginternational.com/AdvancementDegreeofDifficulty.aspx, cited 27 May 2010.
} 
noted that the mission design point shown in Fig. 4 will provide a solar storm warning of approximately three times greater than a spacecraft located at the $\mathrm{L}_{1}$ point. Meanwhile, a $400 \mathrm{~kg}$ SEP spacecraft delivering $150 \mathrm{mN}$ of thrust will provide a solar storm warning of approximately double this. Thus, by hybridising the propulsion systems it is possible to provide a solar storm warning of approximately $8-9$ times greater than a spacecraft located at the $\mathrm{L}_{1}$ point. Correspondingly, the thrust from the SEP system can be reduced, hence increasing the specific impulse and hence propellant lifetime, as well as reducing the sail size to deliver a similar quality of scientific product with a smaller solar sail. As such, through hybridisation the currently mature principle of solar sailing for attitude control can be evolved to enable the disruptive capabilities of solar sailing while maintaining an acceptably low AD2.

\subsection{Engineering Evolutionary}

It is of note that much of the recent solar sail technology development has focused on the CubeSat platform, including NanoSail-D (Johnson et at, 2011), the DLR led Gossamer program (Lura et al, 2010), the Planetary Societies Lightsail-1 (Biddy, 2010; Cantrell \& Friedman, 2010, Nehrenz et al, 2010) and several others (Carroll et al, 2010; Lappas et al, 2010; Pukniel et al 2010). The low-cost nature of CubeSats allows the early risk to be spread over several low-cost missions where a failure can be tolerated much as it was with NanoSail-D and in a fashion which is analogous to the use of sounding rockets by ISAS (now JAXA).

The design specification of a range of currently in development CubeSat solar sails is presented in Fig. 5, together with the design point of IKAROS, GeoSail and Geostorm. It is seen in Fig. 5 that the technological gap between any of the currently in development CubeSat solar sails and, say, GeoSail is rather large, as such these systems will not significantly mitigate the high AD2 of conventional solar sailing. As such, the applicability of these CubeSat solar sails in the classical sense of using SRP to impart a change in energy to an orbit is not clear, especially as the race to be the first spacecraft using SRP as a primary means of propulsion was won by IKAROS. It is of further note from Fig. 5 that due to the absence of supporting booms from the IKAROS sail it offers a significant step towards concepts such as GeoSail in comparison to currently in development CubeSat solar sails. However, if a CubeSat based solar sail system can be successfully developed then it may enable an increased solar sail kite to be incorporated onto a future SEP mission, allowing solar sailing to progress along its development roadmap.

\section{Conclusions}

A solar sail mission catalogue has been developed and presented. The mission catalogue was subdivided into applications which were enabled, or significantly enhanced by solar sailing, of which solar sailing is of marginal benefit and of which solar sailing could be considered unconstructive. Two classes of solar sail mission were identified; Class One, where the solar sail is used to reach a highenergy target and after which the sail can be jettisoned by the spacecraft, and Class Two, where the solar sail is required to maintain a novel or otherwise unsustainable observation outpost. From the catalogue, the key characteristics of solar sail enabled, or significantly enhanced, missions were detailed prior to a detailed discussion of three key applications of solar sailing and the presentation of a solar sail application pull technology development roadmap.

Considering the solar sail application pull technology development roadmap it was noted that the near-term was sparsely populated, with the significant majority of applications clustered in the mid to far term. The concept of a system level Advancement Degree of Difficulty was introduced and it was 
Preprint submitted a special issue of the journal

Advances in Space Research entitled "Solar Sailing: Concepts, Technology, Missions"

illustrated that how through, for example, hybridisation with solar electric propulsion the project risk of solar sailing could be reduced while simultaneously moving the cluster of mid to far term solar sail applications towards the near-term. As such, the Advancement Degree of Difficulty of solar sailing is reduced. Finally, it was noted that the development of CubeSat solar sails potentially offers a first step along the identified reduced Advancement Degree of Difficulty hybridisation roadmap, providing deployment heritage for larger than previously flown solar reflectors, or kites, for spacecraft propulsion.

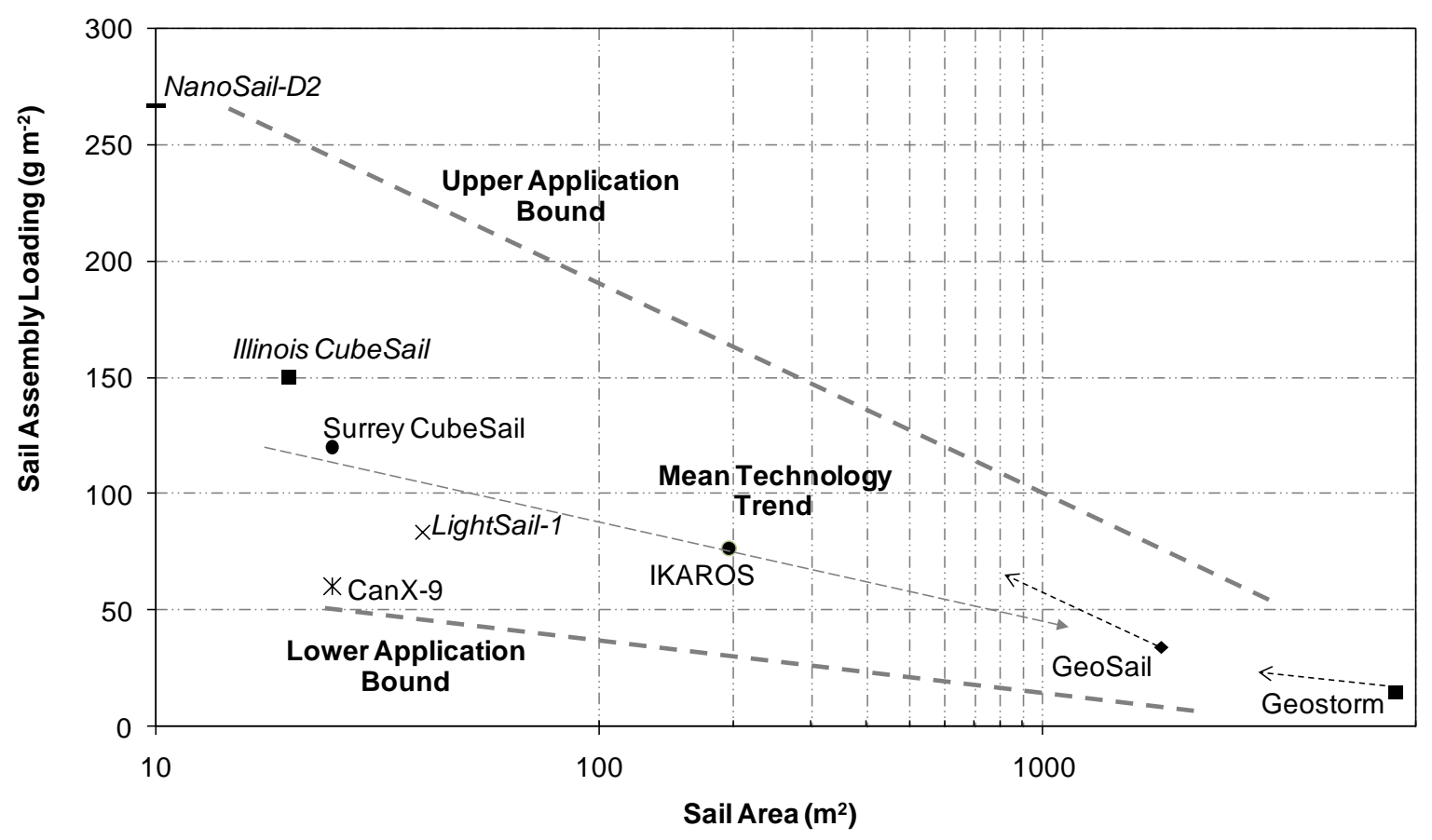

Fig. 5 CubeSat Solar Sail design space. Note, labels in italics indicate assumptions were used to gain sail assembly loading value due to the absence of data within the open literature. 


\section{References}

Alexander D., Sandman A. W., M'Innes C. R., Macdonald M., Ayon J., Murphy N. and Angelopoulos V., GeoSail: A Novel Magnetospheric Space Mission Utilizing Solar Sails, IAC-02-IAA.11.1.04, Electronic Proceedings of the $53^{\text {rd }}$ International Astronautical Congress, Houston Texas, 10-19 October 2002.

Biddy, C., Lightsail, Abstracts of the Second International Symposium on Solar Sailing, ISSS 2010. New York, USA, 20-22 July 2010. Editor J. F. Vazquez-Poritz, pp. 18, 2010.

Biggs, J.D., M'Innes, C.R.: Solar sail formation-flying for deep space remote sensing, Journal of Spacecraft and Rockets, Vol. 46, No. 3, pp. 670-678, 2009.

Cantrell, J., Friedman, L., Lightsail 1 - Flying on Light for Less, Abstracts of the Second International Symposium on Solar Sailing, ISSS 2010. New York, USA, 20-22 July 2010. Editor J. F. VazquezPoritz, pp. 16, 2010.

Carroll, K.A., Spencer, H., Zee, R.E., Vukovich, G., A Nanosatellite Mission to Assess Solar Sail Performance in LEO, Abstracts of the Second International Symposium on Solar Sailing, ISSS 2010. New York, USA, 20-22 July 2010. Editor J. F. Vazquez-Poritz, pp. 56, 2010.

Chen-wan, L.Y., Solar Sail Geostorm Warning Mission Design, AAS 04-107, Proceedings of 14th AAS/AIAA Space Flight Mechanics Conference, Maui, Hawaii, February 2004.

Colasurdo, G., Casalino, L., Optimal Control Law for interplanetary Trajectories with Solar Sail, Advances in the Astronautical Sciences, 109 (3), pp. 2357-2368, 2001.

Dachwald, B., Interplanetary Mission Analysis for Non-Perfectly Reflecting Solar Sailcraft Using Evolutionary Neurocontrol, Advances in the Astronautical Sciences, Vol. 116, Suppl., pp. 1-18, 2004a.

Dachwald, B., Solar Sail Performance Requirements for Missions to the Outer Solar System and Beyond, IAC-04-S.P.11, Proceedings of the 55th International Astronautical Congress of the International Astronautical Federation, the International Academy of Astronautics, and the International Institute of Space Law, Vancouver, Canada, October 2004b.

Dachwald, B., Optimal Solar-Sail Trajectories for Missions to the outer Solar System, Journal of Guidance, Control and Dynamics, 28 (6), pp. 1187 - 1193, 2005.

Driver, J. M., Analysis of an Arctic Polesitter, Journal of Spacecraft and Rockets, 17 (3), pp. 263-269, 1980

Eguchi, S., Ishii, N., Matsuo, H., Guidance Strategies for Solar Sail to the Moon, AAS 93-653, Advances in Astronautical Sciences, 85 (2), pp. 1419-1433, 1993.

Fekete, T.A., Sackett, L. L., von Flotow, A.H., Trajectory Design for Solar Sailing from Low-Earth Orbit to the Moon, AAS 92-184, Advances in Astronautical Sciences, 79 (3), pp. 1083-1094, 1992.

Fimple, W.R., Generalized Three-Dimensional Trajectory Analysis of Planetary Escape by Solar Sail, American Rocket Society Journal, 32, pp. 883-887, 1962. 
Forward, R. L., Statite: A Spacecraft That Does Not Orbit, Journal of Spacecrafts and Rockets, 28 (5), pp. 606-611, 1991

Garner, C.E., Layman, W., Gavit, S.A., Knowles, T., A Solar Sail design For A Mission To The Interstellar Medium, Proceedings of "Space Technology and Applications International Forum", AIP Conference Proceedings 504, NY, pp. 947-961, 2000. Edited by M. El-Genk.

Garner, C., Price, H., Edwards, D., Baggett, Developments And Activities In Solar Sail Propulsion, AIAA-2001-3234, 37 ${ }^{\text {th }}$ AIAA/ASME/SAE/ASEE Joint Propulsion Conference, Salt Lake City, UT, USA, July 2001.

Garwin, R.L., Solar Sailing - A Practical Method of Propulsion Within the Solar System, Jet Propulsion, (28), pp. 188-190, 1958.

Goldstein, B., Buffington, A., Cummings, A. C., Fisher, R., Jackson, B.V., Liewer, P. C., Mewaldt, R. A., and Neugebauer, M., A Solar Polar Sail Mission: Report of a Study to Put a Scientific Spacecraft in a Circular Polar Orbit About the Sun, SPIE International Symposium on Optical Science, Engineering and Instrumentation, July 1998.

Green, A.J., Optimal Escape Trajectories From a High Earth Orbit by Use of Solar Radiation Pressure, T-652, Master of Science Thesis, Massachusetts Institute of Technology, 1977.

Hughes, G.W., Macdonald, M., M'Innes, C.R., Lyngvi, A., Falkner, P., Atzei, A., Sample return from Mercury and other terrestrial planets using solar sail propulsion. Journal of Spacecraft and Rockets, 43 (4). pp. 828-835. 2006.

Irving, J.H., Space Technology, John Wiley \& Sons Inc., New York, 1959.

Janhunen, P, The Electric Sail - A new propulsion method which may enable fast missions to the outer solar system, JBIS, 61, pp. 322-325, August 2008.

Johnson, L., Whorton, M., Heaton, M., Pinson, R., Laue, G., Adams, C., NanoSail-D: A solar sail demonstration mission, Acta Astronuatica, 68 (5-6), pp. 571-575, 2011.

Lappas, V., Visagie, L., Adeli, N., Theodorou, T., Ferndnez, J., Steyn, H., Le Couls, O., Perren, M, CubeSail: A Low Cost Small Cubesat Mission for Solar Sailing and Deorbiting LEO Objects, Abstracts of the Second International Symposium on Solar Sailing, ISSS 2010. New York, USA, 2022 July 2010. Editor J. F. Vazquez-Poritz, pp. 54-55, 2010.

Lawden, D.F., Optimal Escape from a Circular Orbit, Astronautica Acta, 4, pp. 218-234, 1958.

Leipold M., Borg, E., Lingner, S., Pabsch, A., Sachs, R., Seboldt, W., Mercury Sun-Synchronous Polar Orbiter with a Solar Sail, Acta Astronautica, 39 (1-4), pp. 143-151, 1996.

Leipold, M.E., Wagner, O., Mercury Sun-Synchronous Polar Orbits Using Solar Sail Propulsion, J. Guidance, Control and Dynamics, 19 (6), pp 1337-1341, 1996b.

Leipold, M., Wagner, O., Solar Photonic Assist Trajectory Design for Solar Sail Missions to the Outer Solar System and Beyond, Advances in the Astronautical Sciences, 100 (2), pp. 1035-1045, 1998.

Leipold, M., Solar Sail Mission Design, Doctoral thesis, Lehrstuhl für Flugmechanik und Flugregelung; Technische Universität München, DLR-FB-2000-22, 1999. 
Leipold, M., Fichtner, H., Heber, B., Groepper, P., Lascar, S., Burger, F., Eiden, M., Niederstadt, T., Sickinger, C., Herbeck, L., Dachwald, B., Seboldt, W., Heliopause Explorer - A Sailcraft Mission to the Outer Boundaries of the Solar System, Acta Astronautica, 59, pp. 785 - 796, 2006

Leipold, M., Macdonald, M., McInnes, C.R., Eckersley, E., Falkner, P., Agnolon, D., GeoSail System Design for Demonstration of Solar Sailing in Earth Orbit, Abstracts of the Second International Symposium on Solar Sailing, ISSS 2010. New York, USA, 20-22 July 2010. Editor J. F. VazquezPoritz, pp. 13, 2010.

Leipold, M., Lappas, V., Lyngvi, A., Falkner, P., Fichtner, H., Kraft, S., Interstellar Heliopause Probe System Design of a Challenging Mission to 200 AU, Proc. of the Second International Symposium on Solar Sailing, ISSS 2010. New York, USA, 20-22 July, 2010. Editor: R.Ya. Kezerashvili, pp. 111$119,2010 \mathrm{~b}$.

Lura, F., Biering, B., Geppert, U.R.M.E, The Three-Step Gossamer Road Map to Solar Sailing, Proc. of the Second International Symposium on Solar Sailing, ISSS 2010. New York, USA, 20-22 July, 2010. Editor: R.Ya. Kezerashvili, pp. 35-40, 2010.

Lyngvi, A., Falkner, P., Peacock, A., The Interstellar Heliopause Probe, Electronic proceedings of the Tools and Technologies for Future Planetary Exploration, 37th ESLAB Symposium, ESTEC, 2003.

Lyngvi, A., Falkner, P., Kemble, S., Leipold, M., Peacock, A., The Interstellar Heliopause Probe, Acta Astronautica, 57, pp. $104-111,2005$ a.

Lyngvi, A., Falkner, P., Peacock, A., The Interstellar Heliopause Probe Technology Reference Study, Advances in Space Research, 35, pp. 2073 - 2077, 2005 b.

Macdonald M., M'Innes, C. R. GeoSail; An Enhanced Magnetosphere Mission, Using a Small Low Cost Solar Sail, IAF-00-W.1.06, Proceedings of 51 ${ }^{\text {st }}$ International Astronautical Congress, Rio de Janeiro, Brazil, 2-6 October, 2000.

Macdonald M., M'Innes C. R., Alexander D., Sandman A., GeoSail: Exploring the Magnetosphere Using a Low-Cost Solar Sail, Electronic Proceedings of Fifth IAA International Conference on LowCost Planetary Missions, ESA Special Publication SP-542, pp. 341-349, September 2003.

Macdonald M., M'Innes C. R., Analytical Control Laws for Planet-Centred Solar Sailing, Journal of Guidance, Control, and Dynamics, 28 (5), pp. 1038-1048, 2005 a.

Macdonald M., M'Innes C. R., Realistic Earth Escape Strategies for Solar Sailing, Journal of Guidance, Control, and Dynamics, 28 (2), pp 315 - 323, 2005 b.

Macdonald, M. and M'Innes, C.R., Spacecraft planetary capture using gravity assist manoeuvres. Journal of Guidance, Control and Dynamics, 28 (2). pp. 365-369, 2005 c.

Macdonald, M., Hughes, G.W., M'Innes, C.R., Lyngvi, A., Falkner, P., Atzei, A., Solar Polar Orbiter: a Solar Sail Technology Reference Study, Journal of Spacecraft and Rockets, 43 (5). pp. 960-972, 2006.

Macdonald, M., Hughes, G.W., McInnes, C. R., Lyngvi, A., Falkner, P., Atzei, A., GeoSail: An Elegant Solar Sail Demonstration Mission, Journal Spacecraft and Rockets, 44, (4), pp 784 - 796, 2007a. 
Macdonald, M., M'Inees, C.R., Dachwald, B., Heliocentric Solar Sail Orbit Transfers with Locally Optimal Control Laws, Journal of Spacecraft and Rockets, 44 (1), pp. 273 - 276, 2007b

Macdonald, M., McInnes, C.R., Hughes, G.W., Technology requirements of exploration beyond Neptune by solar sail propulsion. Journal of Spacecraft and Rockets, 47 (3)., pp $472-483,2010$.

MacNeal, R.H., Comparison of the Solar Sail with Electric Propulsion Systems, NASA-CR-1986, February 1972.

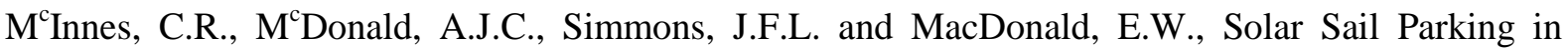
Restricted Three-Body Systems, Journal of Guidance, Dynamics and Control, 17 (2), pp. 399-406, 1994.

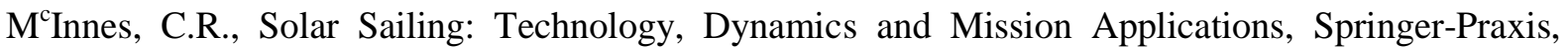
Chichester, 1999.

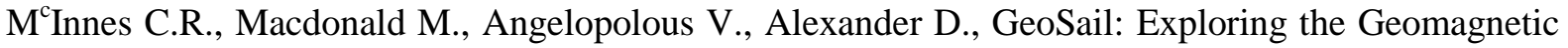
Tail Using a Small Solar Sail, J. Spacecraft and Rockets, 38 (4), pp. 622-629, 2001.

McInnes, C.R., Hughes, G.W., Macdonald, M., Payload mass fraction optimization for solar cargo missions, Journal of Spacecraft and Rockets, 39 (6). pp. 933-935, 2002.

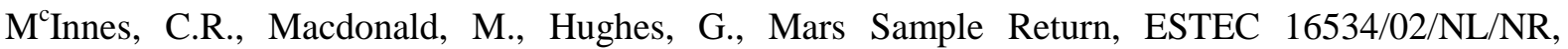
Technical Assistance in the Study of Science Payloads Transported Through Solar Sailing, Technical Note 1, 2003a.

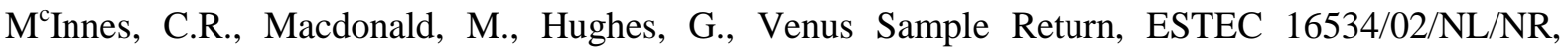
Technical Assistance in the Study of Science Payloads Transported Through Solar Sailing, Technical Note 2, 2003b.

M'Innes, C.R., Macdonald, M., Hughes, G., Mercury Sample Return, ESTEC 16534/02/NL/NR, Technical Assistance in the Study of Science Payloads Transported Through Solar Sailing, Technical Note 3, 2003c.

M'Innes, C.R., Macdonald, M., Hughes, G., Small Body Sample Return, ESTEC 16534/02/NL/NR, Technical Assistance in the Study of Science Payloads Transported Through Solar Sailing, Technical Note 4, 2003d.

M'Innes, C.R., Macdonald, M., Hughes, G., Jupiter Exploration Missions, ESTEC 16534/02/NL/NR, Technical Assistance in the Study of Science Payloads Transported Through Solar Sailing, Technical Note 6, 2003e.

M'Innes, C.R., Macdonald, M., Hughes, G., Jupiter Microsat Explorer Mission, ESTEC 16534/02/NL/NR, Technical Assistance in the Study of Science Payloads Transported Through Solar Sailing, Technical Note 11, 2004a.

M'Innes, C.R., Macdonald, M., Hughes, G., Interstellar Heliopase Prboe, ESTEC 16534/02/NL/NR, Technical Assistance in the Study of Science Payloads Transported Through Solar Sailing, Technical Note 9, 2004b. 
$M^{\mathrm{C}}$ Innes, C.R., Delivering Fast and Capable Missions To The Outer Solar System, Advances in Space Research, 34 (1), pp. 184 - 191, 2004a

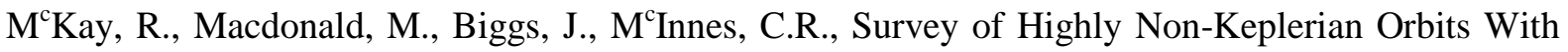
Low-Thrust Propulsion, Journal Guidance, Control and Dynamics, In-Press, 2011.

Matloff, G. L., The Solar Photon Thruster as a Terrestrial Pole Sitter, Annals of the New York Academy of Sciences, 1017, pp. 468-474, 2004

Morgan, T.O., The Inclination Change for Solar Sails and Low Earth Orbit, AAS 79-104, Advances in Astronautical Sciences, 1979.

Mori, O., Tsuda, Y., Sawada, H., Funase, R., Yamamoto, T., Saiki, T., Yonekura, K., Hoshino, H., Minamino, H., Endo, T., Kawaguchi, J., World's First Demonstration of Solar Power Sailing by IKAROS, Abstracts of the Second International Symposium on Solar Sailing, ISSS 2010. New York, USA, 20-22 July 2010. Editor J. F. Vazquez-Poritz, pp. 19-20, 2010.

NASA/JPL Technical Memorandum 33-734, Volume 2, Mariner Venus Mercury 1973 Project Final Report, Extended Mission-Mercury II and III Encounters, 01 December 1975.

NASA/JPL Technical Memorandum 33-734, Volume 1, Mariner Venus Mercury 1973 Project Final Report, Venue and Mercury 1 Encounters, 15 September 1976.

Nehrenz, M., Diaz, A., Svitek, T., Biddy, C., Initial Design and Simulation of the LightSail-1 Attitude Determination and Control System, Proceedings of the Second International Symposium on Solar Sailing (ISSS 2010), The New York City College of Technology of the City University of New York, Editor: R.Ya. Kezerashvili, pp135-140, July 2010.

Normile, D, Mission to Probe Venus's Curious Winds And Test Solar Sail for Propulsion, Science, 328 (5979), p677, 2010.

Oberth, H., Die Rakete zu den Planetenräumen, Oldenbourg, München, 1923. In German.

Oberth, H., Ways to Spaceflight, Verlag, Berlin, 1929 (also NASA TTF-622)

Pagel, G., „Extremale Steuerstrategien für Sonnensegler am Beispiel von Bahntransferproblemen zum Erdmond“, Doctoral Thesis, Technischen Universität Berlin, May 2002. In German.

Pukniel, A., Coverstone, V., Burton, R., Carroll, D., Attitude Control of the CubeSail Solar Sailing Spacecraft in Low Earth Orbit, Proceedings of the Second International Symposium on Solar Sailing (ISSS 2010), The New York City College of Technology of the City University of New York, Editor: R.Ya. Kezerashvili, pp121-126, July 2010.

Sackett, L.L., Optimal Solar Sail Planetocentric Trajectories, R-1113, The Charles Stark Draper Laboratory, Inc., JPL-NASA Contract NAS 7-100 Final Report, 1977.

Sackett, L.L. \& Edelbaum, T.N., Optimal Solar Sail Spiral to Escape, Advances in Astronautical Sciences, AAS/AIAA Astrodynamics Conference, A78 31-901, 1978.

Sauer, Jr., C.G., Optimal Solar Sail Interplanetary Trajectories, American Institute of Aeronautics and Astronautics and American Astronautical Society, Astrodynamics Conference, San Diego, Calif., Aug. 18-20, 1976 
Sauer, Jr., C.G., Solar Sail Trajectories for Solar Polar and Interstellar Probe Missions, Advances in the Astronautical Sciences, 103, pp. 547-562, 2000. Editor Howell, K., Hoots, F., and Kaufman, B.

Sauer, Jr., C.G., The L1 Diamond Affair, AAS 04-278, Proceedings of 14th AAS/AIAA Space Flight Mechanics Conference, Maui, Hawaii, February 2004.

Sands, N., Escape from Planetary Gravitational Fields by Using Solar Sails, American Rocket Society Journal, Vol. 31, pp. 527-531, April 1961.

Sawada, H., Mori, O., Okuizumi, N., Shirasawa, Y., Sakamoto, H., Furuya, H., Matunaga, S., Miyazaki, Y., Report on Deployment Solar Power Sail Mission of IKAROS, Abstracts of the Second International Symposium on Solar Sailing, ISSS 2010. New York, USA, 20-22 July, 2010. Editor: J.F.Vazquez-Poritz, pp. 21, 2010.

Sharma, D.N., Scheeres, D.J., Solar System Escape Trajectories Using Solar Sails, Journal of Spacecraft and Rockets, 41 (4), pp. $684-68,2004$.

Shirley, D., The Mariner 10 Mission to Venus and Mercury, IAF-02-Q.4.1.01, Proceedings of 53rd International Astronautical Congress, Houston, Texas, 10-19 October 2002.

Sweetser, T. H., Sauer, Jr., C. G., Advanced Propulsion Options for Missions to the Kuiper Belt, AAS/AIAA Astrodynamics Specialists Conference, Quebec City, Canada, August, 2001.

Tsander, K., From a Scientific Heritage, NASA Technical Translation TTF-541, 1967, a translation of Iz Nauchnogo Naslediya, Nauca Press, Moscow, 1924.

Tsiolkovsky, K. E., Extension of man into outer space, Proceedings of Symposium on Jet Propulsion, Vol. 2. United Scientific and Technical Presses (NIT), 1936, In Russian.

Tsu, T.C., Interplanetary Travel by Solar Sail, Journal of the American Rocket Society, 29, pp. $422-$ 427, June 1959.

Vulpetti, G., Sailcraft at High Speed by Orbital Angular Momentum Reversal, Acta Astronautica, 40 (10), pp. 733-758, 1997.

Vulpetti, G., Sailcraft Trajectory Options for the Interstellar Probe: Mathematical Theory and Numerical Results, Chapter IV of NASA/CR-2002-211730, "The Interstellar Probe (ISP): PrePerihelion Trajectories and Application of Holography”, 2002.

Vulpetti, G., Johnson, L., Matloff, G.L., Solar Sail: A Novel Approach to Interplanetary Travel, Praxis, New York, 2008.

Wallace, R.A., Precursor Missions to Interstellar Exploration, Proceedings of Aerospace Conference 1999, Vol. 1, pp. 413 420, ISBN: 0-7803-5425-7, 1999.

Wallace, R.A., Ayon, J.A., Sprague, G.A., Interstellar Probe Mission/System Concept, Proceedings of Aerospace Conference 2000, 7, pp. 385 - 396, ISBN: 0-7803-5846-5, 2000.

Waters, T., and McInnes, C.R., Periodic Orbits above the Ecliptic Plane in the Solar Sail Restricted 3body Problem, Journal of Guidance, Control and Dynamics, 30 (3), pp. 687-693, 2007. 
West, J.L., NOAA/NASA/DOD Geostorm Warning Mission, JPL Internal Document, D-13986, October 1996.

West, J.L., Design Issues for a Mission to Exploit the Gravitational Lensing Effect at $500 \mathrm{AU}, 2^{\text {nd }}$ IAA Symposium on Realistic Near-term Advanced Scientific Space Missions, Aosta, Italy, June 1998.

West, J.L., Solar Sail Vehicle System Design For The Geostorm Warning Mission, AIAA-2000-5326, Proceedings of Structures, Structural Dynamics, and Materials Conference, Atlanta, April 2000.

West, J. L., The GeoStorm Warning Mission: Enhanced Opportunities Based On New Technology, 14th AAS/AIAA Spaceflight Mechanics Conference, Paper AAS 04-102, Maui, Hawaii, Feb 8th12th, 2004.

Winglee, R., Slough, J., Ziemba, T.,Goodson, A., Mini-Magnetospheric Plasma Propulsion (M2P2): High Speed Propulsion Sailing the Solar Wind," Proc. STAIF 2000. Edited by M. S. El-genk, AIP 2000 .

Wright, J., Space Sailing, Gordon and Breach Science Publications, Amsterdam, 1992.

Wright, J., Warmke, J., Solar Sailing Mission Applications, Paper No. 76-808, AIAA/AAS Astrodynamics Conference, San Diego, August 1976.

Yen, C. L., Comparing Solar Sail and Solar Electric Propulsions for Propulsive Effectiveness in Deep Space Missions, American Astronautical Society, AAS Paper 01-214, Feb. 2001. 